SMEDLEY : THE CONDENSATION OF CROTONALDEHYDE. 1627

\title{
CLXXXV.-The Condensation of Crotonaldehyde.
}

By Ida Smedley (Beit Memorial Research Fellow).

THE readiness with which aldehydes undergo the aldol condensation in dilute alkaline solutions led Nencki and, later, Magnus Levy to suggest that in the synthesis of fatty acids from carbohydrates which is believed to occur in the animal body, the aldol reaction may take part. Since acetaldehyde may be obtained as a decomposition product of carbohydrates, the production of butyric acid may be assumed to occur by the oxidation and reduction of the aldol formed on condensing two molecules of acetaldehyde. When, however, this hypothesis is applied to explain the formation of the 
higher fatty acids, it is no longer in harmony with our knowledge of the aldol reaction; Lieben and his students investigated a large number of aldehyde condensations, and showed that when the higher fatty aldehydes condense, the resulting aldehydes contain branched carbon chains; the hydrogen atom of a CH group was found to react more readily than that of a $\mathrm{CH}_{2}$ group, the methylene hydrogen more readily than that of a methyl group (Monatsh., $1883,4,10 ; 1901,22,289)$. Thus, the interaction of propaldehyde and acetaldehyde leads to the production of tiglic aldehyde, ${ }^{*}$ and not of the normal chain aldehyde required for the application of this reaction to the synthesis of the fatty acids :

$$
\mathrm{CH}_{3} \cdot \mathrm{CHO}+\mathrm{CH}_{3} \cdot \mathrm{CH}_{2} \cdot \mathrm{CHO}=\mathrm{CH}_{3} \cdot \mathrm{CH}: \mathrm{C}\left(\mathrm{CH}_{3}\right) \cdot \mathrm{CHO} \text {. }
$$

The formation of the unsaturated aldehyde or of the intermediate hydroxy-compound was found to depend on the strength of the alkaline condensing agent used. Previously, Schmidt had described the reaction between furfuraldehyde and propaldehyde as taking place between the furfuraldehyde group and the $\beta$-carbon atom of the propaldehyde; no evidence for this was, however, given, and from Lieben's work it appears improbable that the reaction can take place in this direction (Schmidt, Ber., 1881, 18, 574).

The condensation of aldol was studied by Raper (Trans., 1907, 91, 1831), who obtained the remarkable result that $n$-octoic acid was produced by reducing with hydriodic acid and phosphorus the acid formed by oxidation of the condensation product of aldol. This involved the condensation of the aldehyde group with the hydrogen attached to a $\gamma$-carbon atom. During the condensation a molecule of water was lost, but evidence was lacking as to how this had been eliminated.

The important modification brought about in the aldol reaction by the introduction of a $\beta$-hydroxyl group made it desirable that the influence of other groups should be determined, and the effect of the ethenoid linking on the aldol condensation has, therefore, been examined, crotonaldehyde being chosen for investigation.

The condensation of crotonaldehyde under the influence of acid condensing agents has been investigated by Delépine (Compt. rend., $1910,150,394$ ), who obtained a bimolecular product, $\mathrm{C}_{8} \mathrm{H}_{12} \mathrm{O}_{2}$, boiling at $86-87^{\circ} / 18 \mathrm{~mm}$., to which he attributed a cyclic formula.

The author has now investigated the action of solutions of potassium acetate, potassium carbonate, potassium hydroxide, sodium hydroxide, and guanidine carbonate in varying concentrations on crotonaldehyde; the most favourable conditions appeared

* Tiglic acid, although not known as a constituent of fats, occurs plentifully in nature as a constituent of croton oil. 
to be obtained by dissolving crotonaldehyde in ten times its volume of $N / 10$-potassium carbonate, and leaving the solution for three days at the ordinary temperature. With solutions weaker than $N / 20$ and stronger than $N / 5$, the reaction proceeded more slowly; at $0^{\circ}$ solutions of crotonaldehyde in $N / 10$-potassium carbonate underwent very little change in three days. In each case the amount of potassium carbonate was found to be practically unchanged at the end of the experiment. If, however, dilute solutions of the alkali hydroxides were used, a considerable proportion was neutralised during the course of the experiment, the condensation product apparently undergoing the Cannizzaro reaction (corupare Lieben, loc. cit.). The soluble condensation product decomposed when it was distilled under a pressure of $10-15 \mathrm{~mm}$.; no characteristic crystalline derivatives were obtained from it. By the action of silver oxide an unsaturated hydroxy-acid was obtained, having the formula $\mathrm{C}_{8} \mathrm{H}_{12} \mathrm{O}_{3}$, which absorbed hydrogen in the presence of finely divided platinum; on treating with hydriodic acid and phosphorus it was converted into octoic acid. The difficulties attending the purification and identification of the condensation product are such that it is not possible to say with any degree of certainty whether it is a single substance or a mixture of isomerides. The proportion of the normal eight-carbon chain present in the condensation product is, therefore, uncertain; the detection of $n$-octoic acid in the reduction product establishes, however, that a compound conțaining a straight chain of eight-carbon atoms is formed in the reaction.

Raper's work on the condensation of aldol was repeated, and his final reduction product prepared for comparison with the specimen of octoic acid obtained from the crotonaldehyde condensation product. The yields were in both cases very small, that from the aldol product being rather the better; in each case from 40 grams of the barium salt of the unreduced acid about 0.1 gram of the pure amide was obtained, melting at $103-104^{\circ}$; the melting point was unchanged on mixing together, and each was separately mixed with octoamide prepared from Kahlbaum's pure octoic acid, the melting point of each mixture being unaltered $\left(103-104^{\circ}\right)$. When mixed with the amide of ethylhexoic acid (Raper, loc. cit.), which melts at $101-102^{\circ}$, the melting point was lowered to $95^{\circ}$. There are considerable differences in the melting points assigned by different observers to octoamide; they range from $99^{\circ}$ to $110^{\circ}$; Raper gives $105-106^{\circ}$. After two recrystallisations from water and one from petroleum, the three specimens examined by the author melted at $103-104^{\circ}$. The amide of 1-methylcyclohexane2-carboxylic acid (m. p. $181^{\circ}$ ), which might conceivably be formed 
by the conversion of the straight-chain compound into a cyclic compound, as in the case of the olefinic terpenes, was not detected.

The dimethylcyclopentanecarboxylic acid which might be formed from the branched-chain product is not known, but the identification of the octoic acid seemed convincing. Analysis of the amide obtained partly by the reduction of the crotonaldehyde condensation product and partly from the aldol product gave results agreeing with those required for octoamide.

Since in the condensation of aldol a molecule of water is eliminated, it is possible that this reaction really consists of the condensar tion of a molecule of aldol with one of crotonaldehyde:

$$
\begin{array}{r}
\mathrm{CH}_{3} \cdot \mathrm{CH}(\mathrm{OH}) \cdot \mathrm{CH}_{2} \cdot \mathrm{CHO}+\mathrm{CH}_{3} \cdot \mathrm{CH}: \mathrm{CH} \cdot \mathrm{CHO}= \\
\mathrm{CH}_{3} \cdot \mathrm{CH}(\mathrm{OH}) \cdot \mathrm{CH}_{2} \cdot \mathrm{CH}(\mathrm{OH}) \cdot \mathrm{CH}_{2} \cdot \mathrm{CH}: \mathrm{CH} \cdot \mathrm{CHO} .
\end{array}
$$

In the case of crotonaldehyde, no water appears to be lost during the condensation, and it may be supposed, therefore, that the reaction proceeds as follows:

$$
\begin{aligned}
\mathrm{CH}_{3} \cdot \mathrm{CH}: \mathrm{CH} \cdot \mathrm{CHO}+\mathrm{CH}_{3} \cdot \mathrm{CH}: \mathrm{CH} \cdot \mathrm{CHO}= \\
\mathrm{CH}_{3} \cdot \mathrm{CH}: \mathrm{CH} \cdot \mathrm{CH}(\mathrm{OH}) \cdot \mathrm{CH}_{2} \cdot \mathrm{CH}: \mathrm{CH} \cdot \mathrm{CHO} .
\end{aligned}
$$

It is interesting to compare this structure with that of the widelydistributed group of olefinic terpene compounds, for example, with citral :

Crotonaldehyde condensation product ... $\mathrm{CH}_{3} \cdot \mathrm{CH}: \mathrm{CH} \cdot \mathrm{CH}(\mathrm{OH}){ }^{\cdot} \mathrm{CH}_{2} \cdot \mathrm{CH}: \mathrm{CH} \cdot \mathrm{CHO}$ Citral

$\left(\mathrm{CH}_{3}\right)_{2} \mathrm{C}: \mathrm{CH}^{\bullet} \mathrm{CH}_{2}{ }^{\circ} \mathrm{CH}_{2} \cdot \mathrm{C}^{\circ}\left(\mathrm{CH}_{3}\right): \mathrm{CH} \cdot \mathrm{CHO}$

The relative position of the double bonds is the same as in the crotonaldehyde condensation product, and a consideration of the position of the methyl groups suggests that the terpene chain may be produced by an aldol condensation of a methyl derivative of crotonaldehyde similar to that just described :

$\left(\mathrm{CH}_{3}\right)_{2} \mathrm{C}: \mathrm{CH} \cdot \mathrm{CHO}+\left(\mathrm{CH}_{3}\right)_{2} \mathrm{C}: \mathrm{CH} \cdot \mathrm{CHO}=$ $\left(\mathrm{CH}_{3}\right)_{2} \mathrm{C}: \mathrm{CH} \cdot \mathrm{CH}(\mathrm{OH}) \cdot \mathrm{CH}_{2} \cdot \mathrm{C}\left(\mathrm{CH}_{3}\right): \mathrm{CH} \cdot \mathrm{CHO}$.

Such a product differs from citral only in the substitution of a hydroxyl group for a hydrogen atom. The methyl derivative of crotonaldehyde, $\left(\mathrm{CH}_{3}\right)_{2} \mathrm{C}: \mathrm{CH} \cdot \mathrm{CHO}$, required for this condensation has not yet been prepared; it is possible that in the organism acetone and aldehyde may be condensed so as to produce this compound :

$$
\left(\mathrm{CH}_{3}\right)_{2} \mathrm{CO}+\mathrm{CH}_{3} \cdot \mathrm{CHO}=\left(\mathrm{CH}_{3}\right)_{2} \mathrm{C}: \mathrm{CH} \cdot \mathrm{CHO}+\mathrm{H}_{2} \mathrm{O} \text {, }
$$

although in the laboratory such a synthesis has not yet been effected.

Raper's synthesis of a normal eight-carbon-chain compound and the synthesis, now described, of the same chain from crotonaldehyde suggest that it may be possible by the introduction of ethenoid linkings or hydroxyl groups so to modify the reactivity of the 
compound that the carbonyl group of the higher aldehyde will react with the methyl group of acetaldehyde, and give the normal carbon chains required for the formation of fatty acids.

In the only other case of aldol condensation described in which crotonaldehyde takes part it is perhaps significant that it is the crotonaldehyde carbonyl group that reacts, for the condensation of crotonaldehyde and isobutyraldehyde is described as taking place as follows (Plattensteiner, Monatsh., 1901, 22, 14):

$$
\begin{aligned}
\mathrm{CH} \cdot \mathrm{CH}: \mathrm{CH} \cdot \mathrm{CHO}+\left(\mathrm{CH}_{3}\right)_{2} \mathrm{CH} \cdot \mathrm{CHO}= & \mathrm{CH}_{3} \cdot \mathrm{CH}: \mathrm{CH} \cdot \mathrm{CH}(\mathrm{OH}) \cdot \mathrm{C}\left(\mathrm{CH}_{3}\right)_{2} \cdot \mathrm{CHO} .
\end{aligned}
$$

The author is at present engaged in investigating further the condensation of unsaturated aldehydes.

\section{Expertmental.}

Twenty grams of crotonaldehyde prepared by Delépine's method (Compt. rend., 1908, 147, 1316) were dissolved in 200 c.c. of $N / 10$-potassium carbonate, and the solution left at the ordinary temperature for three days. After about one hour the solution had become yellow. A small amount of a yellow, insoluble oil separated, and at the end of the third day the odour of crotonaldehyde was much fainter. The solution was diluted with 500 c.c. of water, filtered, and neutralised with hydrochloric acid. Excess of barium carbonate was added, and the liquid distilled in a current of steam for from two to three hours. The filtered solution was then concentrated under diminished pressure, and the residue extracted with ether. The ethereal solution, after being dried and evaporated, left a viscous oil, which was placed in a vacuum desiccator over concentrated sulphuric acid for some days:

0.1882 gave $0.4568 \mathrm{CO}_{2}$ and $0.1484 \mathrm{H}_{2} \mathrm{O} . \mathrm{C}=66.21 ; \mathrm{H}=8 \cdot 77$. $\mathrm{C}_{8} \mathrm{H}_{12} \mathrm{O}_{2}$ requires $\mathrm{C}=68.57 ; \mathrm{H}=8.57$ per cent.

The liquid decomposed when distilled under a pressure of $15 \mathrm{~mm}$., and no satisfactory method of further purifying it was found. It reduced Fehling's solution, and deposited a silver mirror on warming with ammoniacal silver nitrate.

In preparing the condensation product for oxidation and subsequent reduction with hydriodic acid, the steam distillation was omitted, and the solution evaporated at about $50^{\circ}$. The amount of the product thus obtained was considerably increased, and the odour of crotonaldehyde could not be detected in it; yet considerable quantities of butyric acid were obtained in the reduction.

Oxidation with Silver Oxide:-A solution of 10 grams of the condensation product was added to 40 grams of silver oxide (freshly precipitated and washed by decantation), and 200 c.c. of

voL. XCIX. 


\section{SMEDLEY : THE CONDENSATION OF CROTONALDEHYDK.}

$N$ /2-barium hydroxide gradually added, the solution being kept cool. After remaining overnight, carbon dioxide was passed into the filtered solution to remove the excess of barium hydroxide. The filtered solution was evaporated to dryness under diminished pressure, extracted with alcohol, the barium salt precipitated by dry ether, and dried at $100^{\circ}$ :

0.1858 gave $0.0970 \mathrm{BaSO}_{4} . \quad \mathrm{Ba}=30.68$.

$$
\left(\mathrm{C}_{8} \mathrm{H}_{11} \mathrm{O}_{3}\right)_{2} \mathrm{Ba} \text { requires } \mathrm{Ba}=30^{\circ} 65 \text { per cent. }
$$

Reduction with Sodium Amalyam:--Reduction with sodium amalgam produced a viscous liquid, which was not satisfactorily characterised. It was dried for eight days in a vacuum desiccator :

0.1065 gave $0.2590 \mathrm{CO}_{2}$ and $0.0940 \mathrm{H}_{2} \mathrm{O} . \quad \mathrm{C}=66.32 ; \mathrm{H}=9 \cdot 81$.

$$
\mathrm{C}_{8} \mathrm{H}_{14} \mathrm{O}_{2} \text { requires } \mathrm{C}=67.60 ; \mathrm{H}=9.86 \text { per cent. }
$$

The product no longer reduced Fehling's solution, nor did it give Schiff's reaction; it still decolorised bromine water, and probably, therefore, contained an unsaturated alcohol.

Reduction of the Acid $\mathrm{C}_{8} \mathrm{H}_{12} \mathrm{O}_{3}$ by Hydrogen in Presence of Finely-divided Platinum:-1.8 Grams of the acid (dried in a desiccator) were dissolved in about 10 c.c. of water, and reduced by shaking with finely-divided platinum in contact with hydrogen at $37^{\circ}$ under a pressure of between $1 \frac{1}{2}$ and 2 atmospheres. When no more hydrogen was absorbed, the filtered solution of the barium salt was evaporated; a deliquescent salt remained, which was dried at $100^{\circ}$ :

$0 \cdot 1454$ gave $0.0745 \mathrm{BaSO}_{4} . \quad \mathrm{Ba}=30 \cdot 12$.

$$
\begin{aligned}
& \left(\mathrm{C}_{8} \mathrm{H}_{13} \mathrm{O}_{3}\right)_{2} \mathrm{Ba} \text { requires } \mathrm{Ba}=30.38 \text { per cent. } \\
& \left(\mathrm{C}_{8} \mathrm{H}_{15} \mathrm{O}_{3}\right)_{2} \mathrm{Ba} \quad, \quad \mathrm{Ba}=30.11 \text { " }
\end{aligned}
$$

The weight of hydrogen absorbed was calculated approximately as 0.0264 gram, whilst 1.8 gram of the barium salt would require 0.0322 gram of hydrogen to saturate it completely.

Reduction with Hydriodic Acid and Red Phosphorus:-Forty grams of the barium salt, $\left(\mathrm{C}_{8} \mathrm{H}_{11} \mathrm{O}_{3}\right)_{2} \mathrm{Ba}$, were heated for five hours with 320 grams of hydriodic acid solution (D 1.7) and 12 grams of red phosphorus. The mixture was diluted, and extracted with ether. After evaporating off the ether, the residual oil was left for twenty-four hours with zinc dust and dilute sulphuric acid, and then distilled in a current of steam. The distillate was neutralised with sodium hydroxide, ${ }^{*}$ extracted with ether, and the ethereal solution evaporated to dryness; about 5-6 grams of a sodium salt were obtained, from which $4-5$ grams of acid were isolated. On distillation, about 3-4 grams passed over below $200^{\circ}$,

* The ethereal extract contained a small quantity of a neutral oil with an aromatic odour; this was not further investigated. 
LATENT HEATS OF VAPORISATION OF MIXED LIQUIDS. 1633

and about 1 gram above $200^{\circ}$. The residue in the flask was converted into the barium salt:

0.1302 gave $0.0726 \mathrm{BaSO}_{4} . \quad \mathrm{Ba}=32.78$.

$\left(\mathrm{C}_{8} \mathrm{H}_{15} \mathrm{O}_{2}\right)_{2} \mathrm{Ba}$ requires $\mathrm{Ba}=32.39$ per cent.

The fraction boiling below $200^{\circ}$ consisted mainly of butyric acid. (Found, $\mathrm{C}=53.57 ; \mathrm{H}=9.34$. Calc., $\mathrm{C}=54.54 ; \mathrm{H}=9.09$ per cent.)

The fraction boiling above $200^{\circ}$ was analysed:

$0 \cdot 1190$ gave $0.2732 \mathrm{CO}_{2}$ and $0 \cdot 1203 \mathrm{H}_{2} \mathrm{O} . \mathrm{C}=62 \cdot 69 ; \mathrm{H}=10 \cdot 11$.

$0.1450 \Rightarrow 0.3340 \mathrm{CO}_{2}, 0.1295 \mathrm{H}_{2} \mathrm{O} . \quad \mathrm{C}=62.84 ; \mathrm{H}=9.93$.

$\mathrm{C}_{4} \mathrm{H}_{8} \mathrm{O}_{2}$ requires $\mathrm{C}=54.54 ; \mathrm{H}=9.09$ per cent.

$\mathrm{C}_{8} \mathrm{H}_{16} \mathrm{O}_{2} \quad, \quad \mathrm{C}=66.66 ; \mathrm{H}=11.11 \quad$ "

This fraction was probably, therefore, a mixture of butyric and octoic acids, and was converted into the amides by Aschan's method (Bcr., 1898, 31, 2348). The small amount of amide formed was recrystallised from petroleum and twice from water; about 0.1 gram (m. p. $103-104^{\circ}$ ) was thus obtained.

Raper's work on the condensation of aldol was repeated, and the same amide obtained in slightly larger amount; a mixture of the two amides melted at 103-104\%. Each was separately mixed with a specimen of octoamide, prepared from Kahlbaum's pure octoic acid, and in neither case was there any lowering of the melting point; each amide was then added to ethylhexoamide (m. p. $101-102^{\circ}$ ), when the melting point fell to $96^{\circ}$.

The specimens of octoamide obtained from aldol and crotonaldehyde were now added together and analysed:

0.0754 gave $0.1845 \mathrm{CO}_{2}$ and $0.0810 \mathrm{H}_{2} \mathrm{O} . \quad \mathrm{C}=66.74 ; \mathrm{H}=11.94$. $\mathrm{C}_{8} \mathrm{H}_{17} \mathrm{ON}$ requires $\mathrm{C}=67 \cdot 13 ; \mathrm{H}=11 \cdot 88$ per cent.

Lister Institute of Preventive Medicine, Cinclsea Gardens, S. W. 